UDK: 621.7/.9

DOI: https://doi.org/10.24867/07AM06Babic

\title{
KONFIGURISANJE UPRAVLJAČKOG SISTEMA NUMERIČKI UPRAVLJANE MAŠINE ALATKE SA HIBRIDNOM KINEMATIKOM
}

\section{CONFIGURING THE CONTROL SYSTEM OF NUMERICALLY CONTROLLED TOOLS MACHINE WITH HYBRID KINEMATICS}

\author{
Aleksandar Babić, Fakultet tehničkih nauka, Novi Sad
}

\section{Oblast: PROIZVODNO MAŠINSTVO}

Kratak sadržaj - Konfiguracija $O-X$ glide hibridnog mehanizma, originalnog, mehanizma razvijenog na FTN$u$ za potrebe gradnje mašina alatki $i$ manipulacionih sistema, podrazumjeva implementaciju nelinearnog kinematskog lanca u upravljački sistem. Hibridni mehanizmi, u koje ovaj mehanizam spada, predstavljaju kombinaciju serijskih $i$ paralelnih mehanizmam formiranu sa ciljem ostvarivanja što boljeg iskorištenja mehaničkih karakteristika. Odabrani upravljački softver, LinuxCNC, je otvorene arhitekture, što znači da se mogu izvršiti promjene u jezgru, u zavisnosti od potrebe, da bi se definisala konfiguracija $i$ na taj način primenom besplatnog softvera realizovati ekpserimentalni prototip mašine alatke.

Ključne reči: $O-X$ glide, Linux $C N C$

Abstract - The configuration of the $O$-X glide hybrid mechanism developed on FTN for the purpose of building machine tools and manipulation systems, involves the implementation of a nonlinear kinematic chain into the control system. The hybrid mechanisms, to which this mechanism belongs, are a combination of serial and parallel mechanisms formed with the aim of maximizing the use of mechanical characteristics. The selected control software, LinuxCNC, has open architecture, which means that changes into core can be made., as needed, to define the configuration and on this way, by implementing free software, to realize experimental prototypes of machine tools.

Keywords: $O-X$ glide, LinuxCNC

\section{UVOD}

Mašina alatka kao rezultat čovjekove vještine, znanja i svijesti da to može i bolje, razvija se kao posljedica razvoja i usavršavanja proizvodnih tehnologija [2].

Napredak mašina alatki obuhvata povećanje režima obrade kod obrade savremenih materijala, poboljšanje mehaničke strukture mašina, modularnost upravljačkih sistema kao i povezivanje u industrijski koncept Internet stvari (Industry Internet of things) [4].

\section{NAPOMENA:}

Ovaj rad proistekao je iz master rada čiji mentor je bio dr Slobodan Tabaković, red. prof.
Razvoj mehatroničkih sistema, da bi se dobile što bolje kinematske karakteristike, utiče na stvaranje paralelne kinematike pogodne za implementaciju u mašine alatke, na slici 1. je prikazana jedna takva mašina.

Zatim, napredovanjem modularne strukture mašina alatki nastala je koncepcija mašina alatki koja omogućava stvaranje fleksibilnih struktura koje su prilagodljive potrebama proizvodnje i geometriji samog proizvoda.

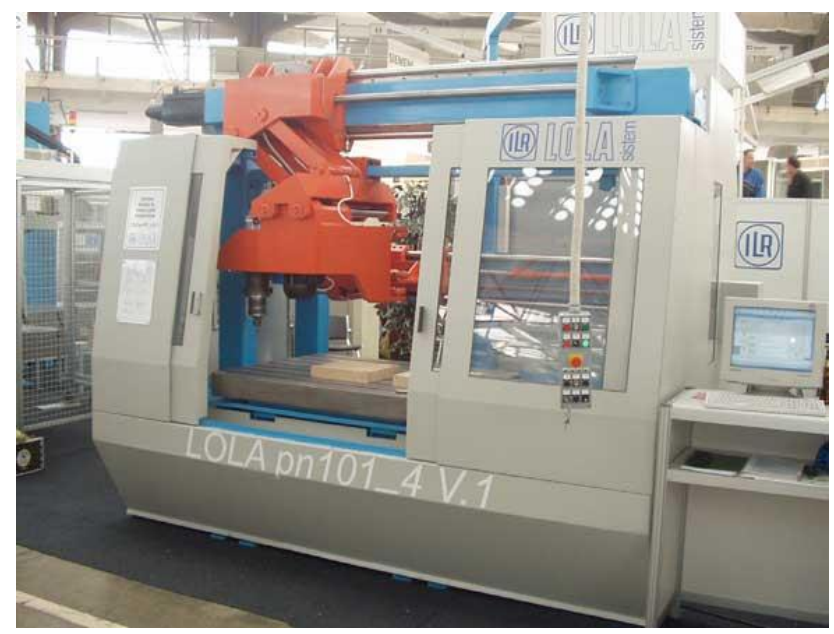

Slika 1. LOLA pn101_4V.1[4]
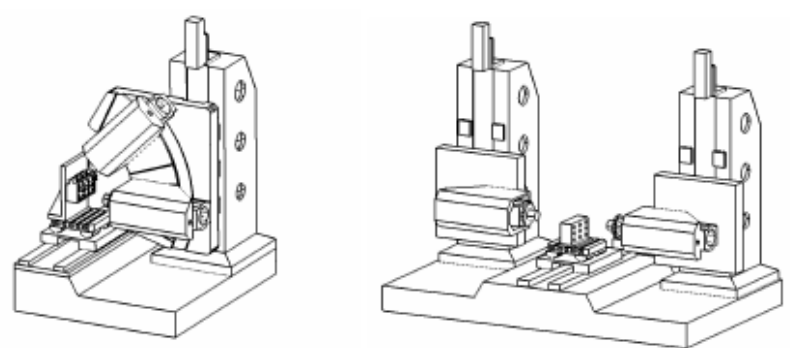

Slika 2. Rekonfigurabilne mašine alatke [4]

Hibridni mehanizmi su nastali kao kombinacija serijskih i paralelnih mehanizama. Cilj njihovog razvoja jeste stvaranje kompromisa između serijske i paralelne kinematike. To podrazumjeva maksimalno iskorištenje prednosti ovih mehanizama, uz minimalne nedostatke [3]. Upravljanje i programiranje mašina alatki po tradiciji komjuterskog numeričkog upravljanja se danas može smatrati kao standardizovanom vještinom koju pokriva veći broj specijalizovanih proizvođača komponenti [2]. 
Za to su zaduženi upravljački sistemi ili upravljačke jednice koji predstavljaju jedan od najvažnijih podsistema numerički upravljanih mašina alatki, pa je njihov zadatak izvršavanje određenih funkcija. Upravljački sistemi mogu biti u vidu hardverski realizovanih kontrolnih jedinica (Fanuc, Siemens) kao i u vidu specijalizovanog softvera (LinuxCNC).

O-X glide mehanizam priprada grupi mehanizama sa hibridnom seijsko paralelnom kinematikom. Razvijen je na Fakultetu tehničkih nauka u Novom Sadu [3]. Njegova konfiguracija podrazumjeva glavni osvrt u ovom radu i vrši se u LinuxCNC okruženju.

LinuxCNC je izabran zbog toga što je besplatan softver, otvorene je arhitekture i može da odgovori na sve postavljenje zahtjeve u ovom slučaju, da bi se riješilo pitanje upravljanja $\mathrm{O}-\mathrm{X}$ glide hibridnog mehanizma

\section{O-X GLIDE}

O-X glide hibridni mehanizam čini ravanski paralelni mehanizam čija se baza sastoji od pokretne platforme, koja je preko sfernih zglobova vezana za četiri štapa konstantne dužine.

$\mathrm{Na}$ drugom kraju, štapovi su vezani za klizače preko zglobova sa jednim rotacionim stepenom slobode kretanja, svaki klizač se kreće po sopstvenoj vođici. Rapored klizača je parni pa su spojeni krutom vezom sa ciljem dobijanja iste brzine i ubrzanja. Grupe klizača raspoređeni su na različitim rastojanjima $u$ pravcu verikale ose od pokretne platforme, što omogućava njihovo mimoilaženje u ravni, a time i dualnost kretanja mehanizma, odnosno kretanje u opruženom (O) i ukrštenom (X) položaju.

Uvođenjem vertikalnih kompenzacionih elemenata, na višim klizačima, vrši se kompenzovanje na rastojanjima između klizača i pokretne platforme. Tako je ostvareno da, zglobovi između štapova i klizača budu pozicionirani $\mathrm{u}$ istoj ravni koja je paralelna sa pokretnom platformom i omogućena je primjena štapova iste dužine što velikim dijelom pojednostavljuje konstrukciju mehanizma.

Na slici 3. prikazan je O-X glide hibrdni mehanizam kao i numerički označeni dijelovi:

1. pokretna platforma;

2. sferni zglobovi;

3. štapovi konstantne dužine;

4. zglobovi sa jednim rotacionim stepenom slobode kretanja;

5. klizači kojima se ostvaruje ravansko kretanje pokretne platforme;

6. vođice klizača kojima se ostvaruje ravansko kretanje pokretne platforme;

7. kruta veza koja spaja klizače (5);

8. kompenzacioni elementi;

9. noseći kontruktivni elementi mehanizma, četiri noge;

10. vođice klizača (11);

11. klizači koji pomjeraju ravanski mehnizam da bi se ostvarilo kretanje duž treće ose, translatorne ose [3].

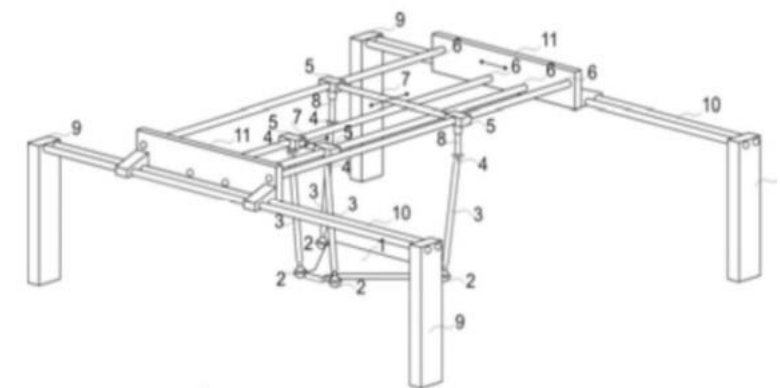

Slika 3. Šematski prikaz O-X glide hibridnog mehanizma [3]

\subsection{Kinematika O-X glide hibridnog mehanizma}

Tokom dizajniranja mašine alatke neophodno je izvršiti analizu kinematskih faktora prilikom kretanja mehanizma.

U ovom slučaju se podrazumjeva analiza brzina pojedinih elemenata mehanizma za maksimalne vrijednosti koje postiže pokretna platforma u mašini alatki [5].

Da bi se sproveo adekvatan izbor vođica, klizača i spojeva, elementa napajanja mašine i dr., neophodna je analiza ubrzanja koja se javljaju na elementima u eksplatacionim uslovima, ali pod maksimalnim opterećenjem pokretne platforme.

Kako bi se izvršila kinematska analiza mehanizma klizanja O-X glide hibridnog mehanizma koristi se inverzna kinematika, koja podrazumjeva podešavanje kretanja pokretne platforme kao i praćenje ponašanja svih zajedničkih elemenata mehanizma. Ovako se mogu dobiti brzine i ubrzanja poprečnih klizača za kretanje pokretne platforme preko teoretskog radnog prostora definisanog brzinom i ubrzanjem.

Kinematska analiza O-X glide hibridnog mehanizma podrazumjeva rješavanje njegove inverzne i direktne kinematike u oba njegova oblika.

$\mathrm{Na}$ slici 4. prikazan je kinematički model O-X glide hibridnog mehanizma na osnovu koga je izvršen proračun kako bi se riješila inverzna i direktna kinematska problematika [5].

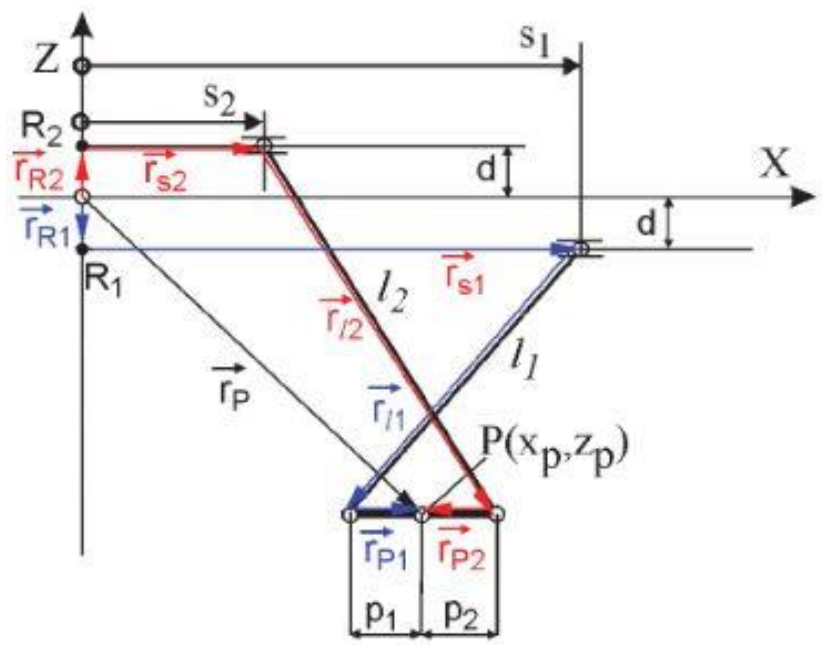

Slika 4. Kinematički model $O$-X glide hibridnog mehanizma [5] 
Inverzna kinematika [5]:

$>\mathrm{Za}$ ukršteni oblik O-X glide hibridnog mehanizma:

$$
\begin{aligned}
& s_{1}=x_{p}-p_{1}+\sqrt{l_{1}^{2}-\left(z_{p}+d\right)^{2}} \\
& s_{2}=x_{p}+p_{2}-\sqrt{l_{2}^{2}+\left(z_{p}-d\right)^{2}}
\end{aligned}
$$

Za opuženi oblik O-X glide hibridnog mehanizma:

$$
\begin{aligned}
& s_{1}=x_{p}-p_{1}-\sqrt{l_{1}^{2}-\left(z_{p}+d\right)^{2}} \\
& s_{2}=x_{p}+p_{1}+\sqrt{l_{2}^{2}-\left(z_{p}-d\right)^{2}}
\end{aligned}
$$

Direktna kinematika [5]:

$$
\begin{gathered}
z_{p}=\frac{-m_{6}-\sqrt{m_{6}^{2}-4 m_{5} m_{7}}}{2 m_{5}} \\
x_{p}=m_{3}+m_{4} * z_{p}
\end{gathered}
$$

\section{LINUXCNC}

Programski sistem LinuxCNC (stariji naziv EMC, (Enhanced machine Controller - Unaprijeđeni mašinski kontroler), ima mogućnost upravljanja mašinama alatkama i robotima kroz kontrolu step i servo motora i drugih uređaja vezanih za kontrolu kretanja.

LinuxCNC može da kontroliše do devet numerički upravljanih osa u koordinatnom kretanju [7].

Programski sistem LinuxCNC sadrži pet osnovnih komponenti:

$>$ (EMCMOT) kontroler pokreta;

$>$ (EMCIO) diskretni I/0 regulator;

$>$ (EMCTASK) izvršilac zadataka koji ih koordinira;

$>$ (GUI) grafičko korisnički interfejs;

$>$ (HAL) hardverski sloj apstrakcije [1].

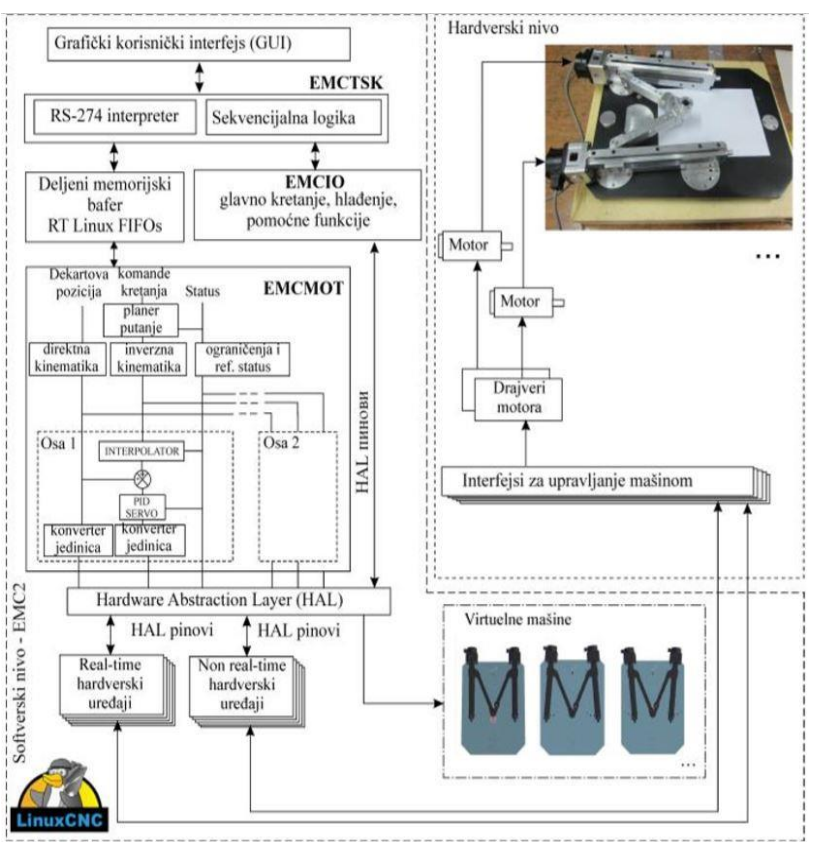

Slika 5. Struktura CNC sistema, otvorena arhitekture na bazi LinuxCNC softvera [1]

\section{KONFIGURACIJA O-X GLIDE HIBRIDNOG MEHANIZMA}

Formiranje konfiguracije je mali istraživački zadatak za svaku mašinu alatku i najčešći je slučaj kada je u pitanju mali budžet projekta u lokalnim uslovima, pa se sprovodi korištenjem sopstvenih resursa [5].

Da bi se mašine sa hibridnom kinematikom kontrolisale neophodno je primjeniti inverzna i direktna rješenja za kontrolu kinematike, pa je pogodnost izabranog LinuxCNC softvera modifikacija i distribucija koda.

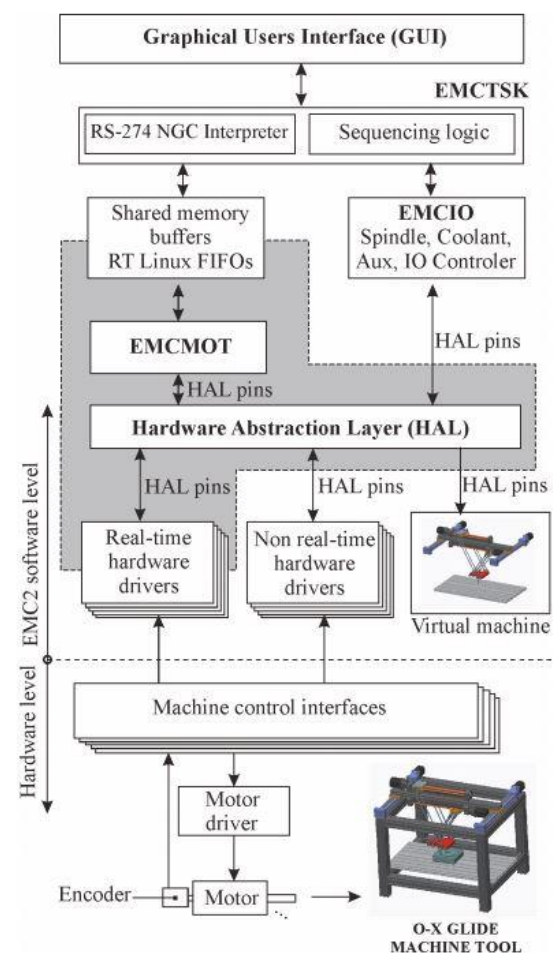

Slika 6. Struktura programskog sistema zasnovanog na CAD/CAM [5]

Promjene, odnosno modifikacije u jezgru podrazumjevaju zamjenu uobičajenih standardnih trivijalnih funkcija inverznih i direktnih kinematika, odgovarajućim funkcijama. Programiranje navedenih funkcija vrši se pomoću programskog jezika $\mathrm{C}$, upotrebljavajući odgovarajuću koriničku datoteku za kinematiku i uključivanje ove datoteke u LinuxCNC-u, u modulu EMCMOT [5].

Integrisanjem modela upravljanja, parametri mašine su takođe definisani, kao i referentni položaj svih osa, a zatim realizacija kompajliranja i povezivanja softvera.

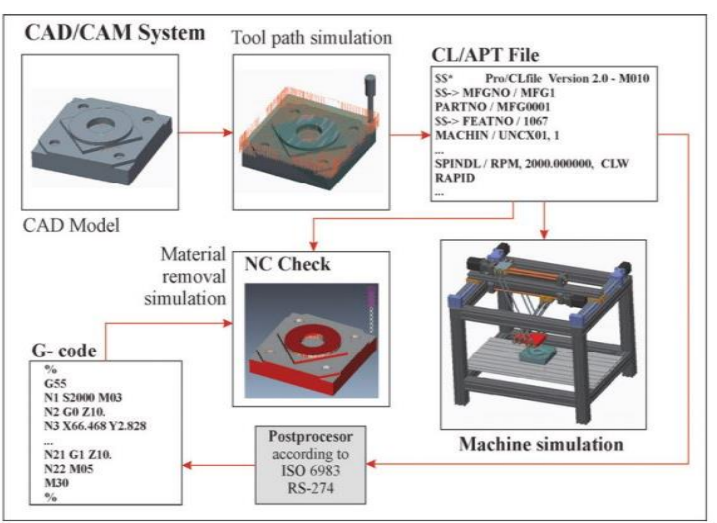

Slika 7. Struktura programskog sistema zasnovanog na CAD/CAM [5] 
Svaka mašina opisana je u LinuxCNC sa nekoliko konfiguracijskih datoteka. HAL datoteka (.hal) sadrži potpune informacije o načinu kao na koji LinuxCNC djeluje sa povezanim hardverom. Među tim hardverskimm komponentama spadaju [6]:

$$
\begin{aligned}
& >\text { akutatori; } \\
& >\text { vretena; } \\
& >\text { referentna tačka; } \\
& >\text { senzori; } \\
& >\text { ulazi i izlazi itd [6]. }
\end{aligned}
$$

Što se tiče konfiguracionih datoteka mašine (.ini) one opisuju parametre mašine:

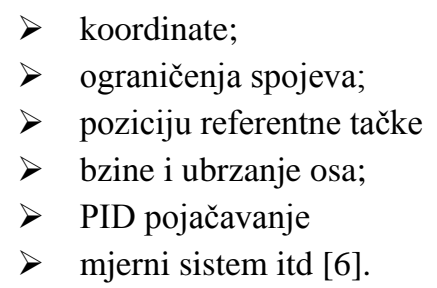

Kada su u pitanje mašina sa netrivijalnom kinematikom potrebno je obezbjediti (.c) datoteku koja izvodi inverzne i direktne transformacije koordinata.

\section{ZAKLJUČAK}

Kao značajna rješenja ovog master rada smatra se: opisana izvodljivost tehnologije virtuelnog prototipa, primjena $\mathrm{O}-\mathrm{X}$ glide hibridnog mehanizma, smanjenje troškova uz korištenje LinuxCNC softvera otvorene arhitekture i sl. Radom je obuhvaćen razvoj O-X glide mehanizma od skice do definisanja svih statičkih i kinematskih aktivnih komponenata, na osnovu čega se vrše detaljnije analize radnog prostora kao i kinematske karakteristike pokretnih elemenata zasnovanih na direktnoj i inverznoj kinematici. $\mathrm{Na}$ osnovu istraživanja moguće je zaključiti da se O-X glide hibridni mehanizam može upotrebljavati pri obradi dijelova prizmatičnog oblika manje visine.

LinuxCNC kao izabrani upravljački sistem, podrazumjeva koncept PC - CNC upravljački sistem, odnosno operativni sistem u realnom vremenu, pa kao takav ima izuzetan potencijal u razvoju mašina alatki složene kinematske strukture u sistemima koji zahtjevaju veću fleksibilnost i rekonfiguraciju, što je potvrđeno u ovom slučaju.

\section{LITERATURA}

[1] S. Živanović, Z. Dimić, G. Vasilić, B. Kokotović, Konfigurisanje virtuelne rekonfigurabilne dvoosne mašine sa paralelnom kinematikom inteegrisane sa CNC sistemom otvorene arhitekture na bazi EMC2 softvera, TEHNIKA - MAŠINSTVO 67 (2018) 4, Beograd, 2018.

[2] S. Živanović, Konfigurisanje novih mašina, doktorska disertacija, mašinski fakultet univerziteta u Beogradu, Beograd, 2010.

[3] C. Mlađenović, S. Tabaković, M. Zeljković, Radni prostor 0-X glide hibridnog mehanizma, DOI: 10.13140/2.1.2874.7522 INFOTEH-JAHORINA, Jahorina, BiH, Vol.: 12, March 2013

[4] S. Tabaković, M. Zeljković, S. Živanović, Savremene mašine alatke - trendovi u edukaciji, Primena novih tehnologija i ideja u školskom inženjerskom obrazovanju, Požega, Srbija, May 15-16, 2017.

[5] S. Živanović, S. Tabaković, M. Zeljković, Configuring a machine tool based on hybrid o-x glide mechanism, Machine design, vol.8(2016) no.4, issn 1821-1259 pp. 141-148, January 2016.

[6] A. Kyrychenko, Open source CNC control for parallel kinematic machine tool, Техніка в сільськогосподарському виробництві, галузеве машинобудування, автоматизація, вun. 26, 2013p, УДК 62-231:621.9.04, Kirovograd National Technical University.

\section{Kratka biografija:}

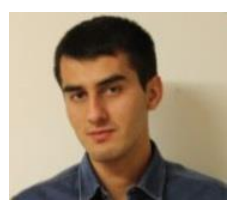

Aleksandar Babić rođen je u Trebinju 1996. god. Master rad na Fakultetu tehničkih nauka iz oblasti Proizvodnog mašinstva - Računaron podržane tehnologije odbranio je 2019.god.

kontakt: aleksandarbabic03@gmail.com 